\title{
Indication creep: physician beware
}

Published at www.cmaj.ca on Sept. 5, 2007.

$\mathrm{T}$ his issue of $C M A J$ features a systematic review (page 725 ) of the use in critically ill patients of erythropoietin, a drug that is widely promoted without an approved indication in this patient population. ${ }^{1}$ Erythropoietin, a complex recombinant glycoprotein hormone, is approved for the treatment of anemia in patients on dialysis, in patients who have had major surgery or in patients undergoing cancer care. The systematic review highlights the finding that when this treatment, which costs about $\$ 400$ per dose, is used offlabel for critically ill patients, it will save, on average, less than I unit of blood, will not improve clinical outcomes and will potentially result in more thrombotic complications.

Johnson \& Johnson and its subsidiary Janssen-Ortho should be commended for investing in several major clinical trials to secure an indication for the use of erythropoietin in critically ill patients. Thanks to this investment, physicians and patients or their loved ones can now make informed choices. But this is where the praise stops. In the United States, erythropoietin manufacturers have been aggressively promoting this drug through direct-to-consumer advertising and incentive payments to physicians. Concerns that these activities have encouraged widespread off-label use with adverse patient consequences have prompted an investigation by the US Congress. ${ }^{2}$

This is not a unique example. Gabapentin, a medication developed for seizures, was illegally marketed for use in chronic pain, subjecting its manufacturer Warner-Lambert to criminal conviction and civil damages. ${ }^{3}$ Activated factor VII, a clotting agent indicated for patients with hemophilia, thus a very small market, has made a fortune for Novo Nordisk as a therapy for massive hemorrhage despite some evidence that it may increase risk of death. ${ }^{4}$ Risperidone, indicated for schizophrenia, has been used off-label an estimated $66 \%$ of the time, ${ }^{5}$ primarily for behavioural disorders in dementia. Only recently was sufficient evidence available to uncover risperidone's increased mortality risk in this context.

Off-label indications typically arise from hypotheses tested in the laboratory or from early clinical or anecdotal observations. Clearly, innovations in care resulting from this should not be curtailed, as this is one avenue to medical advances. Moreover, off-label use is often a logical extension of approved use, such as when biological evidence supports drug efficacy (e.g., antibiotic use guided by in-vitro susceptibility), when use is extended to a physiologically similar disease (e.g., salbutamol for chronic obstructive pulmonary disease) or when a disease afflicts unapproved subgroups (e.g., children).

For physicians to exercise their independent judgment in situations like these is not necessarily problematic. The problem arises when manufacturers use marketing to influence physicians toward off-label use. In theory, pharmaceutical companies are not allowed to promote medication uses that do not have regulatory approval. In practice, aggressive drug promotion spills over into increased off-label use, a consequence that may not be unintended.

Off-label use thereby creates a loophole for drug manufacturers to bypass the regulatory oversight of medications that exists to protect the public. Such use is exceptionally profitable for pharmaceutical companies. One study found that $2 \mathrm{r} \%$ of prescriptions for commonly used medications were for off-label indications, for which $73 \%$ lacked strong scientific evidence. ${ }^{5}$

How can off-label use be controlled? First, clinically reasonable uses must be distinguished from questionable uses. Second, whenever a drug is prescribed, whether on- or offlabel, physicians must inform their patients about pertinent risks and knowledge gaps. Third, the dissemination of information about off-label use, whether online, on paper or in person, must be transparent and ethical. Medical journals, such as $C M A J$, have a key role in highlighting when authors with industry conflicts discuss off-label use. Fourth, pharmaceutical companies must be pressured to verify the appropriateness of off-label use with rigorous clinical trials like those conducted for erythropoietin. Lastly, mechanisms to identify emerging off-label use patterns must be created as an integral part of post-marketing surveillance.

Off-label prescribing can be appropriate when conscientious physicians with a comprehensive understanding of the pertinent available evidence, supplemented by their clinical experience, determine with their patient that it is the best medical option. Off-label use ceases to be appropriate when physicians' autonomy to prescribe is manipulated by drug manufacturers in order to evade onerous and expensive regulatory requirements and expand their market share. Physicians have a duty to be vigilant regarding this phenomenon and to avoid being enablers of the scientifically unsound creep of prescribing indications.

\section{Paul C. Hébert MD MHSc}

Editor-in-Chief, CMAJ

Matthew Stanbrook MD PhD

Deputy Editor, Scientific, $C M A J$

With the Editorial-Writing Team (Barbara Sibbald BJ, Sharon Straus MD MSc, Noni MacDonald MD MSc and Amir Attaran LLB PhD)

\section{REFERENCES}

I. Zarychanski R, Turgeon AF, McIntyre L, et al. Erythropoietin-receptor agonists in critically ill patients: a meta-analysis of randomized controlled trials. CMA 2007; 177:725-34.

2. Mitka M. FDA sounds alert on anemia drugs. JAMA 2007:297:1868-9

3. Henney JE. Safeguarding patient welfare: Who's in charge? Ann Intern Med 2006;145:305-7.

4. O'Connell KA, Wood JJ, Wise RP, et al. Thromboembolic adverse events after use of recombinant human coagulation factor VIIa. JAMA 2006;295:293-8.

5. Radley DC, Finkelstein SN, Stafford RS. Off-label prescribing among office-based physicians. Arch Intern Med 2006;166:102I-6. 